Western University

Scholarship@Western

$4-2020$

\title{
Thermal variability and plasticity drive the outcome of a host- pathogen interaction
}

Laura V. Ferguson

Western University, laura.ferguson@dal.ca

Brent J. Sinclair

Western University, bsincla7@uwo.ca

Follow this and additional works at: https://ir.lib.uwo.ca/biologypub

Part of the Biology Commons

\section{Citation of this paper:}

Ferguson, Laura V. and Sinclair, Brent J., "Thermal variability and plasticity drive the outcome of a hostpathogen interaction" (2020). Biology Publications. 111.

https://ir.lib.uwo.ca/biologypub/111 


\section{Article}

Thermal variability and plasticity drive the outcome of a host-pathogen interaction

Laura V. Ferguson* and Brent J. Sinclair

Department of Biology, The University of Western Ontario, 1151 Richmond Street, London,

ON, Canada, N6A 5B7

*Author for correspondence: laura.ferguson@dal.ca

Current address: Department of Psychology and Neuroscience, Dalhousie University, 1355

Oxford Street, Halifax, NS, Canada, B3H 4J1

Tel: +1-902-799-9726

Key words: fluctuating thermal regime, acclimation, ectotherm, infection, thermal performance Word count: 4994

Elements of the manuscript: main text, tables and figures, supplementary results

Dryad link: https://doi.org/10.5061/dryad.v41nslrrf 


\begin{abstract}
Variable, changing, climates may affect each participant in a biotic interaction differently. We explored the effects of temperature and plasticity on the outcome of a host-pathogen interaction to try to predict the outcomes of infection under fluctuating temperatures. We infected Gryllus veletis crickets with the entomopathogenic fungus Metarhizium brunneum under constant $\left(6{ }^{\circ} \mathrm{C}\right.$, $12{ }^{\circ} \mathrm{C}, 18{ }^{\circ} \mathrm{C}$ or $\left.25^{\circ} \mathrm{C}\right)$ or fluctuating temperatures $\left(6^{\circ} \mathrm{C}\right.$ to $18{ }^{\circ} \mathrm{C}$ or $6{ }^{\circ} \mathrm{C}$ to $\left.25^{\circ} \mathrm{C}\right)$. We also acclimated crickets and fungi to constant or fluctuating conditions. Crickets acclimated to fluctuating conditions survived best under constant conditions if paired with warm-acclimated fungus. Overall, matches and mismatches in thermal performance, driven by acclimation, determined host survival. Mismatched performance also determined differences in survival under different fluctuating thermal regimes: crickets survived best when fluctuating temperatures favoured their performance $\left(6{ }^{\circ} \mathrm{C}\right.$ to $\left.25^{\circ} \mathrm{C}\right)$, compared to fluctuations that favoured fungus performance $\left(6^{\circ} \mathrm{C}\right.$ to $\left.18{ }^{\circ} \mathrm{C}\right)$. Thus, we could predict the outcome of infection under fluctuating temperatures by averaging relative host-pathogen performance under constant temperatures, suggesting that it may be possible to predict responses to fluctuating temperatures for at least some biotic interactions.
\end{abstract}




\section{Introduction}

The success or failure of ectotherms in the face of climate change will depend in large part on their ability to moderate physiological responses through phenotypic plasticity (Deutsch et al. 2008; Somero 2010). In heterogeneous environments, phenotypic plasticity can allow ectotherms, such as insects, to maximise fitness by compensating for the effects of temperature on performance (Angilletta et al. 2002; Angilletta et al. 2006). This capacity for plasticity to improve fitness is complicated by the effects of temperature on the outcomes of biotic interactions: because the parasites and pathogens of ectotherms (including bacteria, viruses, fungi, protozoans and metazoans) are ectotherms themselves, these biotic interactions should be influenced by plasticity of both parties (Altman et al. 2016; Cohen et al. 2017; Stoks et al. 2017). Because insects in temperate regions can spend more than half of their lives overwintering (Williams et al. 2015), their plastic responses to temperature are critical for determining their survival and subsequent performance, and may help to determine the outcome of their interactions with pathogens (Ferguson et al. 2016; Ferguson et al. 2018; Sinclair et al. 2013). However, we know little of how the independent thermal responses of host and pathogen combine to determine the outcome of infection (Altman et al. 2016; Raffel et al. 2012).

The influence of thermal history (i.e. the recent temperature experience) and plasticity (i.e. the physiological response to temperature) on host-pathogen interactions could result in several different outcomes depending on how the performance of each player is matched or mismatched (figure 1, Thomas and Blanford 2003). If hosts and pathogens respond similarly to temperature, such that immunity and pathogenicity shift synchronously, the effects of plasticity on the outcome of the biotic interaction are likely to be negligible (figure 1). However, if the parties 
differ in the magnitude of shifts in performance or the direction and extent of displacement of thermal performance across temperature, mismatches in performance could alter the outcome of the interaction in a temperature-dependent manner (figure 1; Cohen et al. in press; Cohen et al. 2017). Because thermal history shapes thermal performance, matches or mismatches in host and pathogen performance may also depend on the similarity of their thermal histories. Many hostpathogen pairs will experience the same thermal environment prior to infection (e.g. if both host and pathogen live under leaf litter). However, discords in microenvironmental conditions between hosts and pathogens (e.g. mobile hosts moving from variable terrestrial conditions to buffered aquatic habitats, or deliberately transitioning between thermal environments), transitions between hosts occupying thermal niches (e.g. from a mammal to an insect vector), and migration (e.g. encountering a new host "from away") are all likely to produce disparate thermal histories. Thus, to understand how acclimation of host and pathogen will determine the outcome of infection, we must understand the underlying thermal performance of each.

Short-term variation in environmental temperature is also likely to contribute to the outcome of biotic interactions (Stoks et al. 2017) because organisms respond differently to fluctuating temperatures (FTs) compared to constant temperatures (Colinet et al. 2015; Dillon and Woods 2016; Dillon et al. 2016; Kingsolver et al. 2015; Paaijmans et al. 2013; Pamminger et al. 2016). Some of these performance discrepancies between constant and fluctuating temperatures can be explained by the non-linear relationship between performance and temperature (Colinet et al. 2015). Jensen's inequality is a mathematical property of these nonlinear curves: when temperatures fluctuate across the accelerating portion of a thermal performance curve (TPC), the mean of the rate of physiological performance will increase as variation in temperature increases 
(Denny 2017; Sinclair et al. 2016). Thus, the total output of performance at a mean (constant) temperature will usually differ from that under fluctuating conditions (Colinet et al. 2015). Consequently, because terrestrial insects and other animals live in thermally heterogeneous environments we expect that results obtained from experiments at constant temperatures will not accurately predict the effects of fluctuating temperatures (Colinet et al. 2015; Sinclair et al. 2016).

One simple way to translate data from constant temperatures to a world of fluctuating temperatures may be to sum the performance at each of the single temperatures that comprise the fluctuating regime (Colinet et al. 2015). However, most evidence suggests that fluctuating temperatures fundamentally alter physiology (including thermal performance), such that the responses of animals under a fluctuating temperature regime are different from those of their constant temperature counterparts, even when returned to the same constant temperature (Colinet et al. 2015; Kingsolver et al. 2015; Paaijmans et al. 2013). In addition, FTs may cross physiological thresholds such as those that cause injury, modify cell signaling, or encompass physical events like freezing (Marshall and Sinclair 2012). Further, the effects of fluctuating temperatures on performance depend on whether variations in temperature are random or predictable (Raffel et al. 2012), or lead to acclimation (Kingsolver et al. 2015). Thus, we are only beginning to understand the role of thermal variation in determining performance within an individual.

The complexity of fluctuating temperatures may extend to host-pathogen interactions and alter the outcome of infection by modifying the thermal performance of one or both parties (Murdock 
et al. 2012; Paaijmans et al. 2013; Pamminger et al. 2016; Paull et al. 2012; Rohr and Raffel 2010; Terrell et al. 2013). For example, fluctuating temperatures can either increase or decrease susceptibility of aphids to the fungus Erynia neoaphidis compared to their susceptibility at constant temperatures (Blanford et al. 2003). In this example, the outcome of infection under fluctuating temperatures depended on the magnitude of variation in temperature, and whether the host or pathogen crossed physiological thresholds (Blanford et al. 2003). Thus, the outcome of infection under fluctuating temperatures is likely to be complex, making it difficult to predict the outcome of infection (Murdock et al. 2013; Paaijmans et al. 2013). However, the outcome of biotic interactions should rely on the interplay between the thermal performance of host and pathogen (e.g. Figure 1; Sinclair et al. 2016; Thomas and Blanford 2003). Thus, the outcome of these interactions could simply be the sum result of which party wins or loses at each temperature - which makes prediction considerably easier (figure S1).

Our first objective was to determine how fluctuating environments - and particularly those that include low temperatures - influence the outcome of infection. Interactions at low temperatures are an important, yet often overlooked, aspect of host-pathogen interaction (Ferguson et al. 2018). We paired acclimated hosts (Gryllus veletis) and pathogens (Metarhizium brunneum) under either constant or fluctuating temperatures and determined the outcome of infection based on both thermal history and thermal environment during infection. Using hosts and pathogens acclimated to different temperatures allowed us to determine the relative importance of thermal history in both parties under different thermal environments. Our second objective was to determine if we could predict the outcome of infection under fluctuating environments based on the outcome of infection under constant temperatures. We deconstructed the temperatures that 
comprise a simple fluctuating temperature regime (FTR) into two constant temperature components and allowed infections to progress under both constant and fluctuating conditions (Supplementary figure 2B). Our third objective was to test whether the outcome under FTRs is the sum of relative performance under constant temperatures, as opposed to a signal provided by the FTR itself. We used a single switch in temperature (as opposed to repeated fluctuations during an FTR) during infection to determine if the outcome of infection changed to a) mimic the outcome of infection under the latter constant temperature, suggesting an additive effect of performance under FTRs; or b) if the outcome of infection changed to mimic that under FTRs, suggesting that FTRs cross a physiological threshold and fundamentally alter immunity or pathogenicity.

\section{Methods}

Our colony was derived from Gryllus veletis collected in 2010 in Lethbridge, Alberta. We reared G. veletis as described by Coello Alvarado et al. (2015) under constant $25^{\circ} \mathrm{C}$ and $14 \mathrm{~L}$ : $10 \mathrm{D}$ photoperiod with ad libitum water and rabbit chow (Little Friends Rabbit Food, Martin Mills, Elmira, ON, Canada). When crickets reached the $6^{\text {th }}$ instar, we haphazardly assigned females to individual, horizontally-oriented $46 \mathrm{~mL}$ Drosophila vials with paper shelters and ad libitum rabbit chow and water provided in $1.5 \mathrm{~mL}$ tubes with cotton stoppers.

We grew Metarhizium brunneum (Clavicipitaceae: Hypocreales, strain 43a2ii; provided by Michael Bidochka, Brock University, ON, Canada) on potato dextrose agar (PDA) (Kamp and Bidochka 2002) in Parafilm-sealed petri plates under darkness at $25^{\circ} \mathrm{C}$. When we observed 
characteristic green sporulation, we directly transferred spores onto new PDA plates under sterile conditions.

Gryllus veletis overwinter as late instar nymphs in the soil, where they are likely to encounter Metarhizium (Bidochka et al., 1998). Further, because of their limited survival outside of hosts in winter conditions, Metarhizium species are likely to require hosts in which to overwinter (Bidochka et al. 1998). Therefore we expect that G. veletis and M. brunneum interact at both high and low temperatures in the wild. To first determine the effects of fluctuating environments on the outcome of infection, we acclimated crickets in a Sanyo MIR-153 refrigerated incubator for seven days to either constant or fluctuating thermal regimes. We chose a warm acclimation (WA; $\left.25^{\circ} \mathrm{C} ; 14 \mathrm{~L}: 10 \mathrm{D}\right)$ which represented the rearing temperature of the crickets and constant summer conditions. We chose a fluctuating temperature regime that reached a low temperature that produces immunological shifts in G. veletis $\left(6^{\circ} \mathrm{C}\right.$; Ferguson et al. 2016) that was punctuated with warm periods $\left(18^{\circ} \mathrm{C}\right)$ in a simple step-function change with a $12: 12$ photoperiod, thereby mimicking autumn-like conditions. Further, to determine whether the thermal history of the pathogen would also influence the outcome of infection, prior to infection we allowed $M$. brunneum to germinate and sporulate under either $25^{\circ} \mathrm{C}(14 \mathrm{~d}$; constant dark) for infections that progressed under constant warm or fluctuating conditions (figure S2A), or $12{ }^{\circ} \mathrm{C}$ for infection that progressed under constant cold or constant warm ( $28 \mathrm{~d}$; constant dark; supplementary figure 2A).

To infect crickets with M. brunneum, we prepared a suspension of spores for injection following Gao et al. (2011). Briefly, we added 2 mL of $0.01 \%$ Tween 80 (diluted in sterile phosphate- 
buffered saline [PBS]) directly to a plate of sporulating fungus and gently scraped fungal spores into suspension which we strained to remove any large agglutinations. We determined the concentration of M. brunneum spores using a Neubauer improved hemocytometer at $400 \times$ magnification and diluted the suspension in $0.01 \%$ Tween 80 to $5 \times 10^{7}$ spores $/ \mathrm{mL}$. We haphazardly selected crickets from each acclimation regime and paired them with fungi from each acclimation regime, as described above. We injected $1.5 \mu \mathrm{L}$ of fungal spore suspension (7.5 $\times 10^{4}$ spores) into the membrane under the cricket pronotum, using a $10 \mu \mathrm{L}$ Hamilton syringe and 32-gauge needle. We injected control crickets with $1.5 \mu \mathrm{L}$ of Tween 80 . Immediately following injections, we returned crickets to their vials and we then allowed the infection to progress under either constant warm $\left(25^{\circ} \mathrm{C} ; 14: 10 \mathrm{~L}: \mathrm{D}\right)$, fluctuating $\left(6^{\circ} \mathrm{C}\right.$ to $\left.18{ }^{\circ} \mathrm{C} ; 12: 12 \mathrm{~L}: \mathrm{D}\right)$, or constant cold that represented the mean of the fluctuating thermal regime $\left(12{ }^{\circ} \mathrm{C} ; 12: 12 \mathrm{~L}: \mathrm{D}\right)$.We monitored crickets daily for death and confirmed death via M. brunneum by surface-sterilising crickets with $70 \%$ ethanol and observing characteristic green spore growth following sterile incubation at 25 ${ }^{\circ} \mathrm{C}$. Each infection pairing was repeated two or three times with 10-23 crickets infected in each repetition. Preliminary studies demonstrated that infection progressed more rapidly at higher temperatures compared to low temperatures, that mortality plateaued before $200 \mathrm{~h}$ post-infection at $25^{\circ} \mathrm{C}$, and that surviving crickets began to moult to the next instar following more than $240 \mathrm{~h}$ at $25^{\circ} \mathrm{C}$. Thus, we ended our observations at higher temperatures at $240 \mathrm{~h}$. Similarly, we allowed infections at low temperatures to progress until mortality plateaued for 48-72 h. Additionally, we confirmed the viability of the fungal spores used for all injections by plating a sample of each spore suspension on PDA and confirming germination success. 
To determine whether we could explain the outcome of infection under fluctuating temperatures by the sum of performance under constant temperatures, we infected crickets acclimated to warm or fluctuating temperatures with fungus grown under fluctuating conditions (FTR1; constant dark) and allowed infections to progress under two different simple step-function fluctuating thermal regimes $\left(6^{\circ} \mathrm{C}\right.$ to $25^{\circ} \mathrm{C}$ or $6{ }^{\circ} \mathrm{C}$ to $\left.18{ }^{\circ} \mathrm{C}\right)$, as well as constant temperatures that represented the components of these fluctuating thermal regimes (constant $6{ }^{\circ} \mathrm{C}, 18{ }^{\circ} \mathrm{C}$, or $25^{\circ} \mathrm{C}$; figure S2B). Each infection was repeated twice ( $n=5-10$ crickets per repetition). We calculated expected survival under fluctuating temperatures based on the final proportion of host survival under constant temperatures. We summed the final proportion of host survival at each of two constant temperatures that comprised a fluctuating regime and divided by two (i.e. the average survival) as a predicted proportion of survival under fluctuating temperatures.

To determine if a single switch in temperature during infection would mimic the outcome of infection under fluctuating thermal regimes, we infected crickets (WA and FTR1) with fungus grown under fluctuating temperatures (FTR1, constant dark) and transferred crickets to either a constant $6{ }^{\circ} \mathrm{C}$ or $18{ }^{\circ} \mathrm{C}$. At the onset of the first mortality, we switched crickets to the opposing temperature $\left(6^{\circ} \mathrm{C}\right.$ to $18{ }^{\circ} \mathrm{C}$, or $18{ }^{\circ} \mathrm{C}$ to $6{ }^{\circ} \mathrm{C}$; figure $\left.\mathrm{S} 2 \mathrm{C}\right)$. Thus, these switched crickets spent the same amount of time at each temperature as their FTR counterparts, but without the daily fluctuations. We then compared survival under the final temperatures to survival under the same constant conditions without a switch in temperature.

\section{Statistical analysis}

Using the survival package in R (Therneau 2015), we generated Kaplan-Meier survival curves for each pairing of host and pathogen under each environmental temperature. We then created 
generalised linear models of survival and compared the log-likelihood values between models to determine which provided the best fit for our data. To help determine which model would be the best fit for the data, we assessed the shape of the hazard rate over time for each pairing of host and pathogen under each environmental condition. To do so, we generated hazard plots and determined the shape of the distributions based on Cox et al. (Cox et al. 2007). We used a lognormal model to test for differences between curves based on log-likelihood values compared among models and the shape of plotted hazard rates (Cox et al. 2007; Klein et al. 2014). There were no significant among-replicate differences in the curves; thus, we pooled replicates for further analysis. We used an exact test of goodness-of-fit (McDonald 2014) to compare expected and observed survival under both fluctuating thermal regimes.

\section{Results}

\section{Thermal history in both host and pathogen influences the outcome of infection under different thermal regimes}

The outcome of infection changed depending on both the thermal history of the host and pathogen, and on the temperature under which infection progressed. Acclimation to fluctuating temperatures improved cricket survival of infection under constant warm $\left(25^{\circ} \mathrm{C}\right.$; table 1 ; figure $2 \mathrm{~A})$ and constant cold $\left(12{ }^{\circ} \mathrm{C}\right.$; table 1; figure 3$)$ conditions when infected with warm-acclimated fungus. However, when the infection temperature fluctuated from $6{ }^{\circ} \mathrm{C}$ to $18{ }^{\circ} \mathrm{C}$ there was no difference in the survival of crickets when infected with warm-acclimated fungus (table 1; figure 2B), and the outcome of infection did not match the outcome under the mean of the fluctuating regime $\left(12{ }^{\circ} \mathrm{C}\right.$; figure $2 \mathrm{~B}$, figure $\left.3 ; \mathrm{z}=-2.89, \mathrm{p}<0.01\right)$. Further, cold-acclimated fungus negated any benefit the host derived from acclimation to fluctuating temperatures at both $12{ }^{\circ} \mathrm{C}$ (table 1 ; 
figure 3 ) and $25^{\circ} \mathrm{C}$ (table 1). All uninfected control crickets survived under all experimental conditions.

\section{The outcome of infection under fluctuating temperatures approximates the sum of matches or mismatches in thermal performance}

Acclimation to FTR1 again improved survival of crickets compared to a constant warm acclimation, under constant infection temperatures of $6{ }^{\circ} \mathrm{C}$ (figure $4 \mathrm{~A}$ ) and $25^{\circ} \mathrm{C}$ (figure $4 \mathrm{C}$ ); however, at $18{ }^{\circ} \mathrm{C}$ this advantage was lost (figure 4B). Acclimation to fluctuating temperatures also improved survival when infection temperature fluctuated from $25^{\circ} \mathrm{C}$ to $6{ }^{\circ} \mathrm{C}-$ both constant temperatures at which acclimation to fluctuating conditions improved survival (figure 4E). However, this host advantage was again lost when temperatures fluctuated between an advantageous $\left(6^{\circ} \mathrm{C}\right)$ and disadvantageous $\left(18^{\circ} \mathrm{C}\right)$ temperature (figure 4D). No uninfected control crickets died under any of the conditions during the experiments.

To predict the outcome of infection (\% survival) under fluctuating conditions, we calculated the average cricket survival across two constant temperatures as an estimate of survival when temperatures fluctuated between these conditions. We then compared these estimated values to our observed survival rates under fluctuating temperatures. When infection progressed under an FTR of $6{ }^{\circ} \mathrm{C}$ to $18{ }^{\circ} \mathrm{C}$, we predicted $35 \%$ survival of FTR1-acclimated crickets and observed 27 $\%$ survival (exact goodness-of-fit, $\mathrm{p}=0.27$ ). Similarly, we predicted $13 \%$ survival of warmacclimated crickets and observed $16 \%$ survival (figure 5; $\mathrm{p}=0.72$ ). When infection progressed under an FTR of $6{ }^{\circ} \mathrm{C}$ to $25{ }^{\circ} \mathrm{C}$ we predicted $60 \%$ survival of FTR1-acclimated crickets and observed $50 \%$ survival $(\mathrm{p}=0.37)$. Similarly, we predicted $18 \%$ survival of warm-acclimated 
crickets and observed $10 \%$ survival under the same conditions (figure $5 ; \mathrm{p}=0.56$ ). Overall, there were no differences between estimated and observed survival.

\section{Outcome under a single switched temperature is predicted by the outcome under final constant temperature}

When we switched crickets from $18{ }^{\circ} \mathrm{C}$ to $6{ }^{\circ} \mathrm{C}$, their survival of infection matched the outcome

of infection at a constant $6{ }^{\circ} \mathrm{C}$ (table 2; figure 6). When crickets were switched from $6{ }^{\circ} \mathrm{C}$ to 18

${ }^{\circ} \mathrm{C}$, survival time increased compared to infection at a constant $18{ }^{\circ} \mathrm{C}$; however, the overall proportion of cricket survival matched the outcome under constant $18{ }^{\circ} \mathrm{C}$ (table 2; figure 6). Again, all uninfected control crickets survived all experimental conditions. Data underlying all figures are deposited in the Dryad Digital Repository: https://doi.org/10.5061/dryad.v41ns1rrf (Ferguson and Sinclair, 2019).

\section{Discussion}

We explored two aspects of the thermal interactions between hosts and pathogens: 1) the relative contribution of thermal plasticity of performance in the infection biology of pathogens, and immunity of their hosts, and 2) how (and why) fluctuating temperatures affect the outcome of these interactions. We show that the thermal history of both host and pathogen sway the outcome of infection, and that this influence of thermal history interacted with the thermal environment during infection. Further, the effects of fluctuating temperatures on the outcome of infection were two-fold: fluctuating temperatures during acclimation were generally beneficial to hosts, possibly indicating that these conditions provide a signal to broaden the thermal performance of 
immunity. However, fluctuating temperatures during infection appear to oscillate between conditions advantageous to the host and those that favor the pathogen, such that the outcome under fluctuating temperatures is an additive result of host and pathogen performance under constant temperatures.

\section{The thermal history of both pathogen and host contribute to the outcome of infection}

Cricket survival decreased under constant temperatures when infected with cold-acclimated fungus, suggesting that cold-acclimation may have increased the infectivity or virulence of the fungus. Low temperature exposure can decrease pathogen success (Altman et al. 2016; Shocket et al. 2018); in contrast, some microbes such as Yersinia enterocolitica only become pathogenic at low temperatures (Bresolin et al. 2006). In this study, we used a cold-active pathogen that may indeed have evolved to become increasingly infective at low temperatures, thereby taking advantage of this thermal niche. Temperature-mediated changes in infectivity or virulence also indicate that pathogens read cues from their thermal environment to shift their infection potential, before infection actually occurs. Thus, if we are to predict large-scale outcomes of infection, such as seasonal epidemics (Shocket et al. 2018) or disease risk and the fate of pathogens with climate change (Cizauskas et al. 2017; Ferguson et al. 2018), we must include the thermal history of the pathogen and its potential for plasticity into our models.

In contrast to the detrimental effects of infection with cold-acclimated fungus, cricket survival improved under constant temperatures following acclimation to fluctuating temperatures and infection with warm-acclimated or FTR1-acclimated fungus. This increase in survival may result from an increase in immune activity in response to temperature fluctuations (Sinclair et al. 2013; 
Torson et al. 2015). We suggest that the transition from low to high temperatures (or vice-versa) may trigger a prophylactic increase in immunity (Greenspan et al. 2017), thereby modifying host physiology and the outcome of infection. For example, both Megachile rotundata and Anopheles stephensi increase expression of antimicrobial peptide genes following exposure to fluctuating temperatures (Murdock et al. 2013; Torson et al. 2015), which suggests that fluctuating temperatures are immunostimulatory in insects. It is unclear whether or not this increase in immune activity is adaptive, or maintained across all types of fluctuating temperatures (Ferguson et al. 2018; Greenspan et al. 2017). It will next be important to explore why fluctuating temperatures stimulate immunity, and how this will impact host-pathogen interactions under increasing climatic variability.

Although we detected plasticity in both the host and the pathogen, their thermal performance did not necessarily acclimate in the same direction. Crickets maintained their improved survival following acclimation to a fluctuating thermal environment even when infected with FTR1acclimated fungus (e.g. figure 4A, C, E), which suggests that hosts and pathogens do not necessarily match their performance when acclimated to the same conditions. For example, cold acclimation improves immunity in tadpoles of Lithobates clamitans, but induces injury or dormancy in its trematode pathogen, Ribeiroia ondatrae (Altman et al. 2016). This apparent mismatch in host-pathogen responses to temperature suggests that although both hosts and pathogens are capable of thermal acclimation, we cannot expect that acclimation to the same conditions will result in matched performance. Indeed, environmental conditions may exert different selective pressures on pathogens compared to hosts (Cizauskas et al. 2017) and mismatches in thermal performance occur under natural conditions (Cohen et al. in press; Cohen 
et al. 2017) in which we might expect both host and pathogen to acclimate to similar thermal environments. Further, thermal plasticity may be selected for or constrained by the diversity of pathogens and pathogen thermal performance that a host encounters, or vice versa, by the generalization or specialization of a pathogen to its hosts. Thus, it is likely that the thermal environment can produce different challenges or opportunities for hosts and pathogens. Mismatched acclimation responses may then be linked to the interaction of immunity and infectivity with other complex physiological processes related to temperature (e.g. stress tolerance, reproduction), and balancing potential encounters with hosts or pathogens with diverse thermal breadths. Overall, thermal plasticity of host and pathogen contribute to producing mismatches in thermal performance that then interact with the thermal environment during infection to modify the outcome of this interaction.

\section{Performance under constant conditions predicts the outcome under fluctuating conditions}

Our ability to detect matches and mismatches in thermal performance is essential to our ability to predict the outcome of infection under different thermal environments (Cohen et al. 2017). If we extrapolate relative thermal performance curves (TPCs) of host and pathogen, based on host survival at constant temperatures, we can detect such mismatches in performance (figure 7C,D). The survival of warm-acclimated crickets varies little across temperature, suggesting matched TPCs between host and pathogen (figure 7A,B). By contrast, acclimation to fluctuating temperatures produces a putative mismatch in performance between the host and the fungus (figure 7C;D). This mismatch is masked when temperatures fluctuate between those that are advantageous to the host and those that are advantageous to the pathogen, thereby explaining the 
illusion of matched performance. Thus, in these cases, we suggest we will only be able to detect mismatches in performance by creating TPCs from performance at constant temperatures. Overall, thermal performance curves created from performance at constant temperatures are likely to be an essential, heuristic tool for predicting the outcome of infection, and possibly other biotic interactions, under different thermal environments (Cohen et al. 2017; Ferguson et al. 2018; Sinclair et al. 2016; Stoks et al. 2017).

Because of the complexity and non-additive nature of fluctuating temperatures on individual performance, predicting the outcomes of biotic interactions under fluctuating conditions is inherently complex (Colinet et al. 2015; Sinclair et al. 2016; Vazquez et al. 2017). However, in our system, by creating TPCs from the outcome of infection at constant temperatures, we could then predict the outcome of infection under fluctuating conditions. Mismatched TPCs explained why cricket survival decreased under an FTR of $6{ }^{\circ} \mathrm{C}$ to $18{ }^{\circ} \mathrm{C}$, as conditions fluctuated between those advantageous to the cricket and those advantageous to the fungus (figure 7). We also demonstrated that the outcome of infection was not simply a product of a different mean temperature experienced during fluctuating conditions, as the outcome of infection was not matched under these two conditions. Further, we then predicted that if conditions fluctuate between two conditions advantageous to the host (e.g. $6{ }^{\circ} \mathrm{C}$ and $25^{\circ} \mathrm{C}$; figure 7 ), host survival should improve - and indeed, this prediction matched our observations. When we simply average host survival at the constant temperatures that comprise an FTR, our predictions approximate our observed outcomes (figure 5B), which suggests that we can estimate not only the direction, but also the change in magnitude of survival of a host under fluctuating conditions. If this is a general property of host-pathogen interactions (or a subset thereof), we may be able to 
choose relevant constant temperatures to observe outcomes of infection and extrapolate to fluctuating conditions, rather than performing infections ad nauseum under myriad different fluctuating thermal regimes (Colinet et al. 2015) to inform predictive models. To achieve this predictive ability, we must next understand how generalizable our results are to other taxa of both hosts and pathogens. Our ability to generalize will depend on whether the mechanisms underlying temperature-induced changes in immunity and infectivity are consistent among species (Ferguson et al., 2018; Kaunisto et al., 2016). We did not directly measure these physiological traits in this study but suggest that measures of individual performance (e.g. immune activity) will be necessary to build on our ability to predict the outcome of infection under different thermal environments.

A single switch in temperature could provide a signal to host or pathogen that accounts for changes in the outcome of infection under fluctuating temperatures. For example, Litoria caerula frogs increase immune activity and better survive fungal infection following a single increase in temperature to $21{ }^{\circ} \mathrm{C}$, compared to a decrease of the same magnitude to $21^{\circ} \mathrm{C}$, suggesting that an increase in temperature may signal for an adaptive increase in resistance to pathogens (Greenspan et al. 2017). In contrast, cricket survival following a single temperature switch in this study appeared to correspond with whether the new temperature was advantageous to the host or the pathogen, as survival matched the outcome of constant temperature regimes instead of a fluctuating temperature regime. Thus, regardless of the complex effects of temperature and plasticity on individual performance (Colinet et al. 2015), we suggest that the outcomes of biotic interactions under fluctuating temperatures can be reduced (in some instances) to the sum of 
relative physiological performance between players. The challenge is to understand and generalise the circumstances under which this extrapolation is meaningful.

Although we suggest that a simple approach is adequate to predict the outcome of this biotic interaction under variable thermal environments, we cannot dismiss the inherent complexity of fluctuating thermal environments altogether (Vazquez et al. 2017). Some pathogens may rapidly acclimate during infection (Raffel et al. 2012; Rohr et al. 2018), optimising their thermal performance throughout fluctuating conditions (and thus outperforming their host in any given thermal environment). Similarly, random fluctuations in temperature (Raffel et al. 2012), climatic extremes (Kingsolver and Buckley 2017; Stoks et al. 2017) and genotype (Blanford et al. 2003; Vale and Little 2009) will also affect thermal performance and the outcome of biotic interactions in ways that we have not explored in this work. Finally, we recognise that the interaction between photoperiod and temperature is likely to affect acclimation responses and the outcome of infection; thus, it may be necessary to disentangle these two variables to further understand the impact of fluctuating temperatures on host-pathogen interactions. Next, it will be important to explore our limits of predictability, and how these simplified predictions extend to other biotic interactions (such as predator-prety interactions; Stoks et al. 2017) under fluctuating environments.

\section{Conclusions}

Here we demonstrate that acclimation to fluctuating temperatures increases survival of G. veletis to infection and that growth at low temperatures modifies pathogen performance. Thus, both host and pathogen thermal history contribute to the outcome of infection under different thermal 
environments. Further, we show that matched thermal histories do not necessarily result in matched performance between host and pathogen. Finally, we demonstrate that the outcome of the interaction between G. veletis and M. brunneum under fluctuating temperatures is a product of the sum of these interactions under constant temperatures. As such, we may be able to use the outcome of the interaction under constant temperatures to extrapolate relative performance, and then predict the outcome of these interactions under variable thermal environments.

\section{Acknowledgements}

We thank Dr. Michael Bidochka for providing the fungus used in this study, Dr. Yolanda Morbey for advice on statistical analysis and comments on an earlier version of the manuscript, Dr. Graham Thompson, Dr. Barb Katzenback, Dr. Beth MacDougall-Shackleton, Dr. Rodney Dekoter, and Kurtis Turnbull for comments on an earlier draft, and Dr. Lauren Des Marteaux for the cricket drawings. We are grateful to the reviewers and editors for their insightful comments and suggestions that greatly improved the manuscript. This work was supported by the Natural Sciences and Engineering Research Council of Canada (NSERC) via a Discovery Grant to BJS and a Post-Graduate Doctoral Scholarship to LVF.

\section{References}

Altman, K. A., S. H. Paull, P. T. Johnson, M. N. Golembieski, J. P. Stephens, B. E. LaFonte, and T. R. Raffel. 2016. Host and pathogen thermal acclimation responses depend on the stage of infection. Journal of Animal Ecology 85:1014-1024.

Angilletta, M. J., P. H. Niewiarowski, and C. A. Navas. 2002. The evolution of thermal physiology in ectotherms. Journal of Thermal Biology 27:249-268. 
Angilletta, M. J. J., A. F. Bennett, H. Guderley, C. A. Navas, F. Seebacher, and R. S. Wilson. 2006. Coadaptation: a unifying principle in evolutionary thermal biology. Physiological and Biochemical Zoology 79:282-294.

Bidochka, M. J., J. E. Kasperski, and G. A. M. Wild. 1998. Occurrence of the entomopathogenic fungi Metarhizium anisopliae and Beauveria bassiana in soils from temperate and nearnorthern habitats. Canadian Journal of Botany 76:1198-1204.

Blanford, S., M. B. Thomas, C. Pugh, and J. K. Pell. 2003. Temperature checks the red queen? Resistance and virulence in a fluctuating environment. Ecology Letters 6:2-5.

Bresolin, G., J. A. Morgan, D. Ilgen, S. Scherer, and T. M. Fuchs. 2006. Low temperatureinduced insecticidal activity of Yersinia enterocolitica. Molecular Microbiology 59:503512.

Cizauskas, C. A., C. J. Carlson, K. R. Burgio, C. F. Clements, E. R. Dougherty, N. C. Harris, and A. J. Phillips. 2017. Pathogen vulnerability to climate change: an evidence-based functional trait approach. Royal Society Open Science 4:160535.

Coello Alvarado, L. E., H. A. MacMillan, and B. J. Sinclair. 2015. Chill-tolerant Gryllus crickets maintain ion balance at low temperatures. Journal of Insect Physiology 77:15-25.

Cohen, J. M., D. J. Civitello, M. D. Venesky, T. A. McMahon, and J. R. Rohr. Under review. Thermal mismatches explain how climate change and infectious disease drove widespread amphibian extinctions. bioRxiv. https://doi.org/10.1101/164814.

Cohen, J. M., M. D. Venesky, E. L. Sauer, D. J. Civitello, T. A. McMahon, E. A. Roznik, and J. R. Rohr. 2017. The thermal mismatch hypothesis explains host susceptibility to an emerging infectious disease. Ecology Letters 20:184-193.

Colinet, H., B. J. Sinclair, P. Vernon, and D. Renault. 2015. Insects in fluctuating thermal environments. Annual Review of Entomology 60:123-140.

Cox, C., H. Chu, M. F. Schneider, and A. Muñoz. 2007. Parametric survival analysis and taxonomy of hazard functions for the generalized gamma distribution. Statistics in Medicine 26:4352-4374.

Denny, M. 2017. The fallacy of the average: on the ubiquity, utility and continuing novelty of Jensen's inequality. Journal of Experimental Biology 220:139-146.

Deutsch, C. A., J. J. Tewksbury, R. B. Huey, K. S. Sheldon, C. K. Ghalambor, D. C. Haak, and P. R. Martin. 2008. Impacts of climate warming on terrestrial ectotherms across latitude. Proceedings of the National Academy of Science U S A 105:6668-6672.

Dillon, M. E., and H. A. Woods. 2016. Introduction to the Symposium: Beyond the mean: biological impacts of changing patterns of temperature variation. Integrative and Comparative Biology 56:11-13.

Dillon, M. E., H. A. Woods, G. Wang, S. B. Fey, D. A. Vasseur, R. S. Telemeco, K. Marshall et al. 2016. Life in the frequency domain: the biological impacts of changes in climate variability at multiple time scales. Integrative and Comparative Biology 56: 1-13

Ferguson, L. V., D. E. Heinrichs, and B. J. Sinclair. 2016. Paradoxical acclimation responses in the thermal performance of insect immunity. Oecologia 181:77-85.

Ferguson, L. V., R. Kortet, and B. J. Sinclair. 2018. Eco-immunology in the cold: the role of immunity in shaping the overwintering survival of ectotherms. The Journal of Experimental Biology 221: 13873

Ferguson, L. V. and B. J. Sinclair. 2019. Data from: Thermal variability and plasticity drive the outcome of a host-pathogen interaction. American Naturalist, Dryad Digital Repository, https://doi.org/10.5061/dryad.v41ns1rrf. 
Gao, Q., M. J. Bidochka, and G. J. Thompson. 2011. Effect of group size and caste ratio on individual survivorship and social immunity in a subterranean termite. Acta Ethologica 15:55-63.

Greenspan, S. E., D. S. Bower, R. J. Webb, L. Berger, D. Rudd, L. Schwarzkopf, and R. A. Alford. 2017. White blood cell profiles in amphibians help to explain disease susceptibility following temperature shifts. Developmental and Comparative Immunology 77:280-286.

Kamp, A. M., and M. J. Bidochka. 2002. Conidium production by insect pathogenic fungi on commercially available agars. Letters in Applied Microbiology 35:74-77.

Kaunisto, S., L.V. Ferguson, and B. J. Sinclair. 2016. Can we predict the effects of multiple stressors on insects in a changing climate? Current Opinion in Insect Science. 17: 55-61.

Kingsolver, J. G., and L. B. Buckley. 2017. Quantifying thermal extremes and biological variation to predict evolutionary responses to changing climate. Philosophical Transactions of the Royal Society of London B 372: 20160147

Kingsolver, J. G., J. K. Higgins, and K. E. Augustine. 2015. Fluctuating temperatures and ectotherm growth: distinguishing non-linear and time-dependent effects. Journal of Experimental Biology 218:2218-2225.

Klein, J. P., H. C. van Houwelingen, J. G. Ibrahim, and T. H. Scheike. 2014, Handbook of survival analysis. Boca Raton, Florida, USA, Taylor \& Francis Group.

Marshall, K. E., and B. J. Sinclair. 2012. The impacts of repeated cold exposure on insects. Journal of Experimental Biology 215:1607-1613.

McDonald, J. H. 2014. Handbook of Biological Statistics ( $3^{\text {rd }}$ ed.). Sparky House Publishing, Baltimore, Maryland. 29-39.

Murdock, C. C., L. L. Moller-Jacobs, and M. B. Thomas. 2013. Complex environmental drivers of immunity and resistance in malaria mosquitoes. Proceedings of the Royal Society B 280:20132030.

Murdock, C. C., K. P. Paaijmans, A. S. Bell, J. G. King, J. F. Hillyer, A. F. Read, and M. B. Thomas. 2012. Complex effects of temperature on mosquito immune function. Proceedings of the Royal Society B 279:3357-3366.

Paaijmans, K. P., R. L. Heinig, R. A. Seliga, J. I. Blanford, S. Blanford, C. C. Murdock, and M. B. Thomas. 2013. Temperature variation makes ectotherms more sensitive to climate change. Global Change Biology 19:2373-2380.

Pamminger, T., T. Steier, and S. Tragust. 2016. High temperature and temperature variation undermine future disease susceptibility in a population of the invasive garden ant Lasius neglectus. Naturwissenschaften 103:46.

Paull, S. H., B. E. LaFonte, and P. T. J. Johnson. 2012. Temperature-driven shifts in a hostpathogen interaction drive nonlinear changes in disease risk. Global Change Biology 18:3558-3567.

Raffel, T. R., J. M. Romansic, N. T. Halstead, T. A. McMahon, M. D. Venesky, and J. R. Rohr. 2012. Disease and thermal acclimation in a more variable and unpredictable climate. Nature Climate Change 3:146-151.

Rohr, J. R., D. J. Civitello, J. M. Cohen, E. A. Roznik, B. Sinervo, and A. I. Dell. 2018. The complex drivers of thermal acclimation and breadth in ectotherms. Ecology Letters 21:1425-1439. 
Rohr, J. R., and T. R. Raffel. 2010. Linking global climate and temperature variability to widespread amphibian declines putatively caused by disease. Proceedings of the National Academy of Sciences U S A 107:8269-8274.

Shocket, M. S., D. Vergara, A. J. Sickbert, J. M. Walsman, A. T. Strauss, J. L. Hite, M. A. Duffy et al. 2018. Pathogen rearing and infection temperatures jointly influence disease transmission and shape seasonality of epidemics. Ecology 99:1975-1987.

Sinclair, B. J., L. V. Ferguson, G. Salehipour-shirazi, and H. A. MacMillan. 2013. Crosstolerance and cross-talk in the cold: relating low temperatures to desiccation and immune stress in insects. Integrative and Comparative Biology 53:545-556.

Sinclair, B. J., K. E. Marshall, M. A. Sewell, D. L. Levesque, C. S. Willett, S. Slotsbo, Y. Dong et al. 2016. Can we predict ectotherm responses to climate change using thermal performance curves and body temperatures? Ecology Letters 19:1372-1385.

Somero, G. N. 2010. The physiology of climate change: how potentials for acclimatization and genetic adaptation will determine 'winners' and 'losers'. Journal of Experimental Biology 213:912-920.

Stoks, R., J. Verheyen, M. Van Dievel, and N. Tuzun. 2017. Daily temperature variation and extreme high temperatures drive performance and biotic interactions in a warming world. Current Opinion in Insect Science 23:35-42.

Terrell, K. A., R. P. Quintero, S. Murray, J. D. Kleopfer, J. B. Murphy, M. J. Evans, B. D. Nissen et al. 2013. Cryptic impacts of temperature variability on amphibian immune function. Journal of Experimental Biology 216:4204-4211.

Therneau, T. M. 2015.A Package for Survival Analysis in R.

Thomas, M. B., and S. Blanford. 2003. Thermal biology in insect-pathogen interactions. Trends in Ecology \& Evolution 18:344-350.

Torson, A. S., G. D. Yocum, J. P. Rinehart, W. P. Kemp, and J. H. Bowsher. 2015. Transcriptional responses to fluctuating thermal regimes underpinning differences in survival in the solitary bee Megachile rotundata. Journal of Experimental Biology. 218: 1060-1068.

Vale, P. F., and T. J. Little. 2009. Measuring pathogen fitness under genetic and thermal variation. Heredity 103:102-109.

Vazquez, D. P., E. Gianoli, W. F. Morris, and F. Bozinovic. 2017. Ecological and evolutionary impacts of changing climatic variability. Biological Reviews 92:22-42.

Williams, C. M., H. A. Henry, and B. J. Sinclair. 2015. Cold truths: how winter drives responses of terrestrial organisms to climate change. Biological Reviews 90:214-235. 
Table 1. Statistical comparisons of survival among groups of differentially-acclimated Gryllus veletis infected with acclimated Metarhizium brunneum.

\begin{tabular}{|c|c|c|c|c|c|c|}
\hline \multicolumn{2}{|c|}{ Comparison between acclimation groups } & Fungal growth temperature & Infection temperature & $\mathbf{Z}$ & df & $\mathbf{P}$ \\
\hline Warm $(n=42)$ & FTR1 $(n=40)$ & Warm & $25^{\circ} \mathrm{C}$ & 2.83 & 1 & $<0.01$ \\
\hline Warm $(\mathrm{n}=19)$ & FTR1 $(n=21)$ & Warm & FTR1 & -0.08 & 1 & 0.94 \\
\hline Warm $(n=26)$ & FTR1 $(n=28)$ & Warm & $12^{\circ} \mathrm{C}$ & 2.05 & 1 & 0.04 \\
\hline Warm $(n=20)$ & FTR1 $(\mathrm{n}=15)$ & Cold & $12^{\circ} \mathrm{C}$ & 0.58 & 1 & 0.57 \\
\hline $\begin{array}{l}\text { FTR1 + cold } \\
\text { fungus }\end{array}$ & FTR1+ warm fungus & - & $12^{\circ} \mathrm{C}$ & -2.11 & 1 & 0.03 \\
\hline $\begin{array}{l}\text { Warm + cold } \\
\text { fungus }\end{array}$ & Warm + warm fungus & - & $12^{\circ} \mathrm{C}$ & -0.45 & 1 & 0.65 \\
\hline $\begin{array}{l}\text { Warm + cold } \\
\text { fungus }\end{array}$ & FTR1 + warm fungus & - & $12^{\circ} \mathrm{C}$ & -8.69 & 1 & 0.01 \\
\hline $\begin{array}{l}\text { Warm + warm } \\
\text { fungus }\end{array}$ & FTR $1+$ cold fungus & - & $12^{\circ} \mathrm{C}$ & 0.09 & 1 & 0.93 \\
\hline Warm $(\mathrm{n}=21)$ & FTR1 $(\mathrm{n}=20)$ & Cold & $25^{\circ} \mathrm{C}$ & -0.11 & 1 & 0.91 \\
\hline
\end{tabular}

Using a lognormal model, we compared survival of crickets acclimated to warm, $\left(25^{\circ} \mathrm{C}, 7 \mathrm{~d}\right)$ and fluctuating thermal regimes (FTR 1 ; $18{ }^{\circ} \mathrm{C} 12 \mathrm{~h} ; 6{ }^{\circ} \mathrm{C} 12 \mathrm{~h}$ ). Infections progressed at constant or fluctuating temperatures. P-values in bold type represent significant differences. Sample sizes of crickets are included at first mention of each acclimation group. 
Table 2. Statistical comparison of survival among acclimated Gryllus veletis under constant and fluctuating thermal regimes.

\begin{tabular}{|c|c|c|c|c|c|}
\hline \multicolumn{2}{|c|}{$\begin{array}{c}\text { Comparison between acclimation } \\
\text { groups }\end{array}$} & \multirow{2}{*}{$\begin{array}{c}\text { Infection } \\
\text { conditions } \\
6^{\circ} \mathrm{C}\end{array}$} & \multirow{2}{*}{$\begin{array}{c}\mathbf{Z} \\
2.32\end{array}$} & \multirow{2}{*}{$\begin{array}{c}\mathbf{d f} \\
1\end{array}$} & \multirow{2}{*}{$\begin{array}{c}\mathbf{P} \\
0.02\end{array}$} \\
\hline $\operatorname{FTR} 1(n=20)$ & Warm $(\mathrm{n}=18)$ & & & & \\
\hline FTR1 $(n=20)$ & Warm $(\mathrm{n}=18)$ & $18^{\circ} \mathrm{C}$ & 0.30 & 1 & 0.76 \\
\hline FTR1 $(n=20)$ & Warm $(n=20)$ & $25^{\circ} \mathrm{C}$ & -2.82 & 1 & $<0.01$ \\
\hline FTR1 $(n=22)$ & Warm $(\mathrm{n}=19)$ & FTR1 & 0.72 & 1 & 0.47 \\
\hline FTR1 $(n=20)$ & Warm $(n=20)$ & FTR2 & -3.28 & 1 & 0.001 \\
\hline $\operatorname{FTR}(\mathrm{n}=10)$ & Warm $(\mathrm{n}=10)$ & $\begin{array}{l}6^{\circ} \mathrm{C} \text { to } 18^{\circ} \mathrm{C} \\
\text { switch }\end{array}$ & 2.31 & 1 & 0.02 \\
\hline FTR $(n=10)$ & Warm $(\mathrm{n}=10)$ & $\begin{array}{l}18{ }^{\circ} \mathrm{C} \text { to } 6^{\circ} \mathrm{C} \\
\text { switch }\end{array}$ & 1.94 & 1 & 0.05 \\
\hline
\end{tabular}

Gryllus veletis were acclimated to either warm $\left(25{ }^{\circ} \mathrm{C} 7 \mathrm{~d}\right)$ or fluctuating (FTR1; $6{ }^{\circ} \mathrm{C} 12 \mathrm{~h} ; 18{ }^{\circ} \mathrm{C}$ 12h; $7 \mathrm{~d}$ ) conditions and infected with Metarhizium brunneum acclimated to FTR1 conditions. Infections then progressed under constant or fluctuating conditions. We compared survival between warm and FTR1 using a lognormal model. Under switch conditions, infections began at one constant temperature and were switched to another at the point at which mortality began. FTR2 $=25{ }^{\circ} \mathrm{C} 12 \mathrm{~h} ; 6{ }^{\circ} \mathrm{C} 12 \mathrm{~h}$. Values in bold type face represent significant differences between groups. 
Figure legends

Figure 1. Examples of potential plasticity in response to low temperatures in both host and pathogen thermal performance leading to matches or mismatches in their interaction. Grey panels show the thermal performance curves of unacclimated (solid lines) and acclimated hosts (dashed lines) or pathogens (dotted lines). Middle panels include the possible outcome of the host-pathogen interaction, based on the sum of performance of each player. The zero mark indicates matched performance; above the zero indicates advantage to the host (i.e. host wins), below the zero indicates advantage to the pathogen (i.e. pathogen wins). Dashed lines represent the outcome if only the host acclimates; dotted lines represent the outcome if only the pathogen acclimates; dashed and dotted lines represent the outcome when both parties acclimate to the thermal conditions.

Figure 2. Host acclimation modifies the outcome of the interaction between Gryllus veletis and Metarhizium brunneum. We acclimated female Gryllus veletis to constant warm $\left(25^{\circ} \mathrm{C}\right)$ or autumn-like fluctuating temperatures (FTR1; $6{ }^{\circ} \mathrm{C} 12 \mathrm{~h} ; 18{ }^{\circ} \mathrm{C} 12 \mathrm{~h}$ ) for $7 \mathrm{~d}$ and then challenged them with the entomopathogenic fungus Metarhizium brunneum grown under warm $\left(25^{\circ} \mathrm{C}\right)$ conditions. Infections then progressed under A. constant warm $\left(25^{\circ} \mathrm{C}\right)$ or B. fluctuating conditions (FTR1). Asterisks denote significant differences in survival between host acclimation groups.

Figure 3. Survival of Gryllus veletis females at $12{ }^{\circ} \mathrm{C}$ following infection with warm- or cold-acclimated Metarhizium brunneum. Grey lines indicate host survival of infections with warm-acclimated fungus $\left(25^{\circ} \mathrm{C}\right)$; black lines indicate infections with cold-acclimated fungus (12 $\left.{ }^{\circ} \mathrm{C}\right)$. We acclimated crickets to either warm conditions $\left(25^{\circ} \mathrm{C}\right)$ or fluctuating conditions (FTR1; 6 
${ }^{\circ} \mathrm{C} 12 \mathrm{~h} ; 18{ }^{\circ} \mathrm{C} 12 \mathrm{~h}$ ) for $7 \mathrm{~d}$. Letters indicate significant differences between host acclimation groups.

Figure 4. The outcome of infection under constant versus fluctuating conditions. We acclimated female Gryllus veletis to warm $\left(25^{\circ} \mathrm{C}\right)$ or fluctuating temperatures (FTR $1 ; 6^{\circ} \mathrm{C} 12 \mathrm{~h}$; $18{ }^{\circ} \mathrm{C} 12 \mathrm{~h}$ ) for $7 \mathrm{~d}$ and then challenged them with the entomopathogenic fungus Metarhizium brunneum acclimated to fluctuating temperatures (FTR1, as for crickets). Infections progressed at constant $(\mathrm{A}, \mathrm{B}, \mathrm{C})$, or fluctuating conditions $(\mathrm{D}, \mathrm{E})$. Asterisks indicate host survival curves that differ significantly.

Figure 5. Prediction of outcome of infection under fluctuating temperatures based on outcomes under constant temperatures. A. Outcome of infection under constant temperatures. B. Outcome of infection under fluctuating temperatures. Predicted values under FTs are derived from the average of the proportion of host survival under the two constant temperatures that comprise the FTR; for example, we averaged survival under constant $6{ }^{\circ} \mathrm{C}$ and $25^{\circ} \mathrm{C}$ to predict survival under an FTR of $6^{\circ} \mathrm{C}$ to $25^{\circ} \mathrm{C}$. Final survival was assessed at $384 \mathrm{~h}$ post-infection (PI) $\left(6{ }^{\circ} \mathrm{C}\right.$; FTR1), $220 \mathrm{~h}$ PI $\left(25^{\circ} \mathrm{C}\right) ; 320 \mathrm{~h}$ PI (FTR2) and $150 \mathrm{~h}$ PI $\left(18^{\circ} \mathrm{C}\right)$.

Figure 6. The outcome of infection (proportion of host survival) under a switched thermal regime. We acclimated female Gryllus veletis to warm $\left(25^{\circ} \mathrm{C}\right)$ or fluctuating temperatures (FTR1; $6{ }^{\circ} \mathrm{C} 12 \mathrm{~h} ; 18{ }^{\circ} \mathrm{C} 12 \mathrm{~h}$ ) for $7 \mathrm{~d}$ and then challenged them with the entomopathogenic fungus Metarhizium brunneum acclimated to fluctuating temperatures (FTR1, as for crickets). Infections began at either $18{ }^{\circ} \mathrm{C}(\mathrm{A})$ or $6{ }^{\circ} \mathrm{C}(\mathrm{B})$ and then switched to $6{ }^{\circ} \mathrm{C}$ and $18{ }^{\circ} \mathrm{C}$, respectively, when mortality began (the time of the switch is represented with an arrow). Dotted lines represent outcomes of infection at constant $6^{\circ} \mathrm{C}(\mathrm{A})$ or $18^{\circ} \mathrm{C}(\mathrm{B})$ from figure 3 . Letters denote significant differences among curves within a panel. 
Figure 7. Relative thermal performance of host and pathogen at constant temperatures determines the outcome of infection under fluctuating conditions. Putative thermal performance curves of WA and FTR-acclimated hosts and FTR-acclimated pathogen, determined by host survival at constant temperatures. Equal signs denote where pathogen and host are equally matched and the outcome of infection does not change across temperature.

Positive sign indicates the temperature at which the host outperforms the pathogen, and negative sign indicates where the pathogen outperforms the host. A./B. Warm-acclimated host (dashed black line) and FTR-acclimated pathogen (solid line) are equally matched and thus the outcome of infection is unaffected by fluctuating temperatures, whether temperatures fluctuate between 6 and 18 (A) or $6{ }^{\circ} \mathrm{C}$ and $25^{\circ} \mathrm{C}$ (B). C. FTR-acclimated hosts (dashed grey line) broaden thermal performance and outperform the pathogen (solid line) at $6{ }^{\circ} \mathrm{C}$; however, the pathogen outperforms the host at $18{ }^{\circ} \mathrm{C}$. Thus, under a fluctuating thermal regime of $6{ }^{\circ} \mathrm{C}$ to $18{ }^{\circ} \mathrm{C}$, survival is a product of alternating thermal advantages. D. Under a fluctuating thermal regime of $6{ }^{\circ} \mathrm{C}$ to $25^{\circ} \mathrm{C}$, host survival increases because both temperatures are advantageous to the host. 

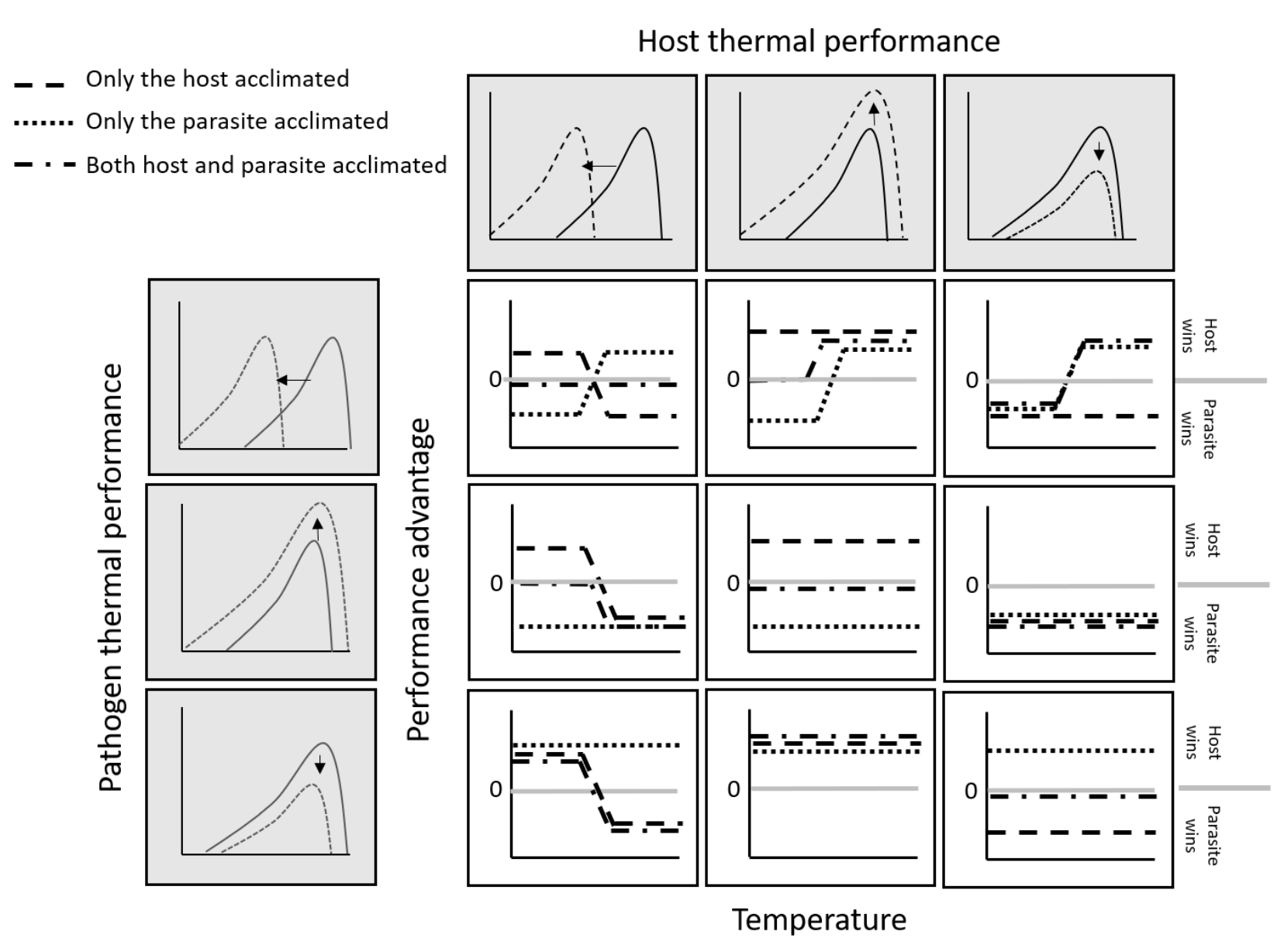

Figure 1. 


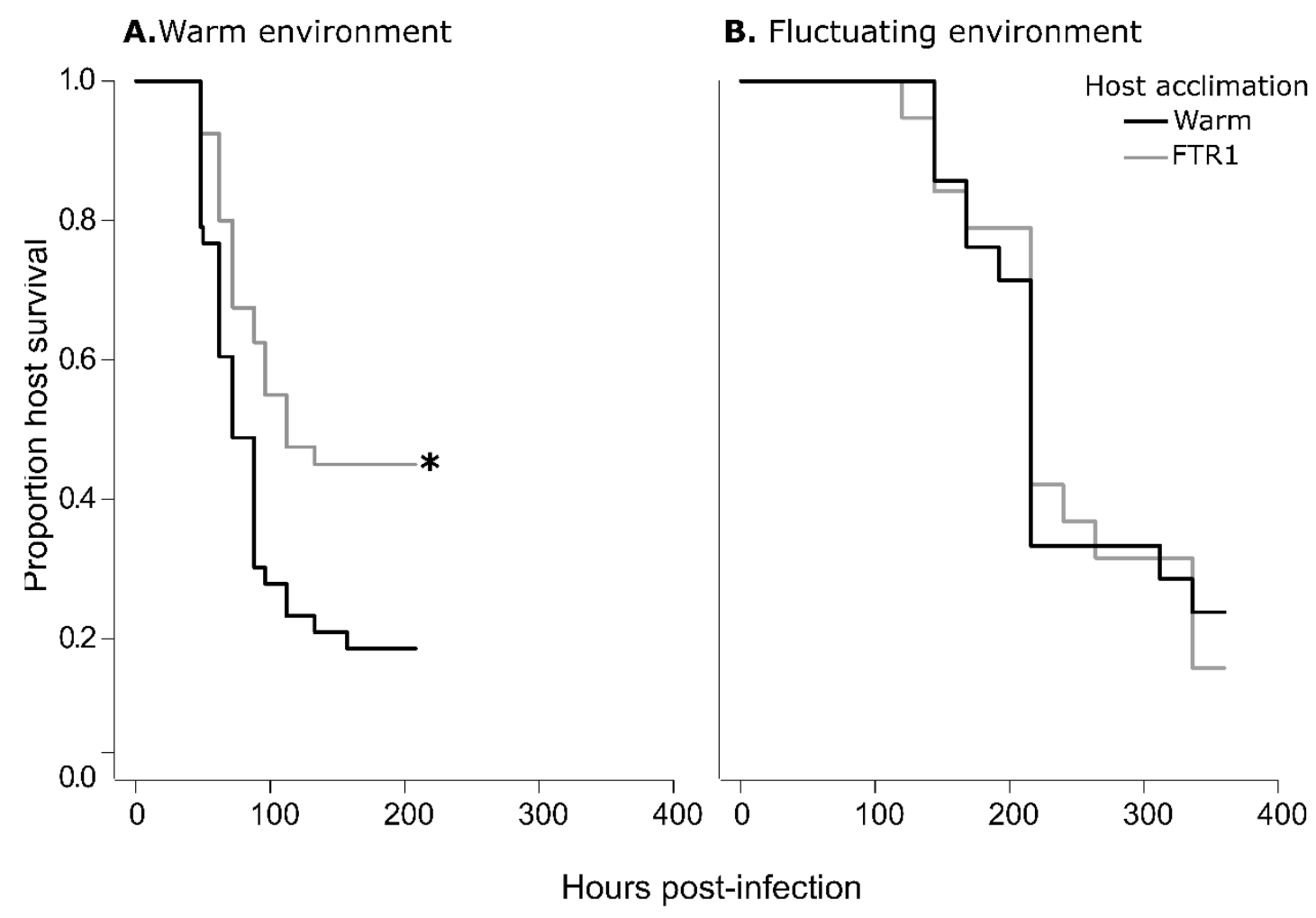

Figure 2. 


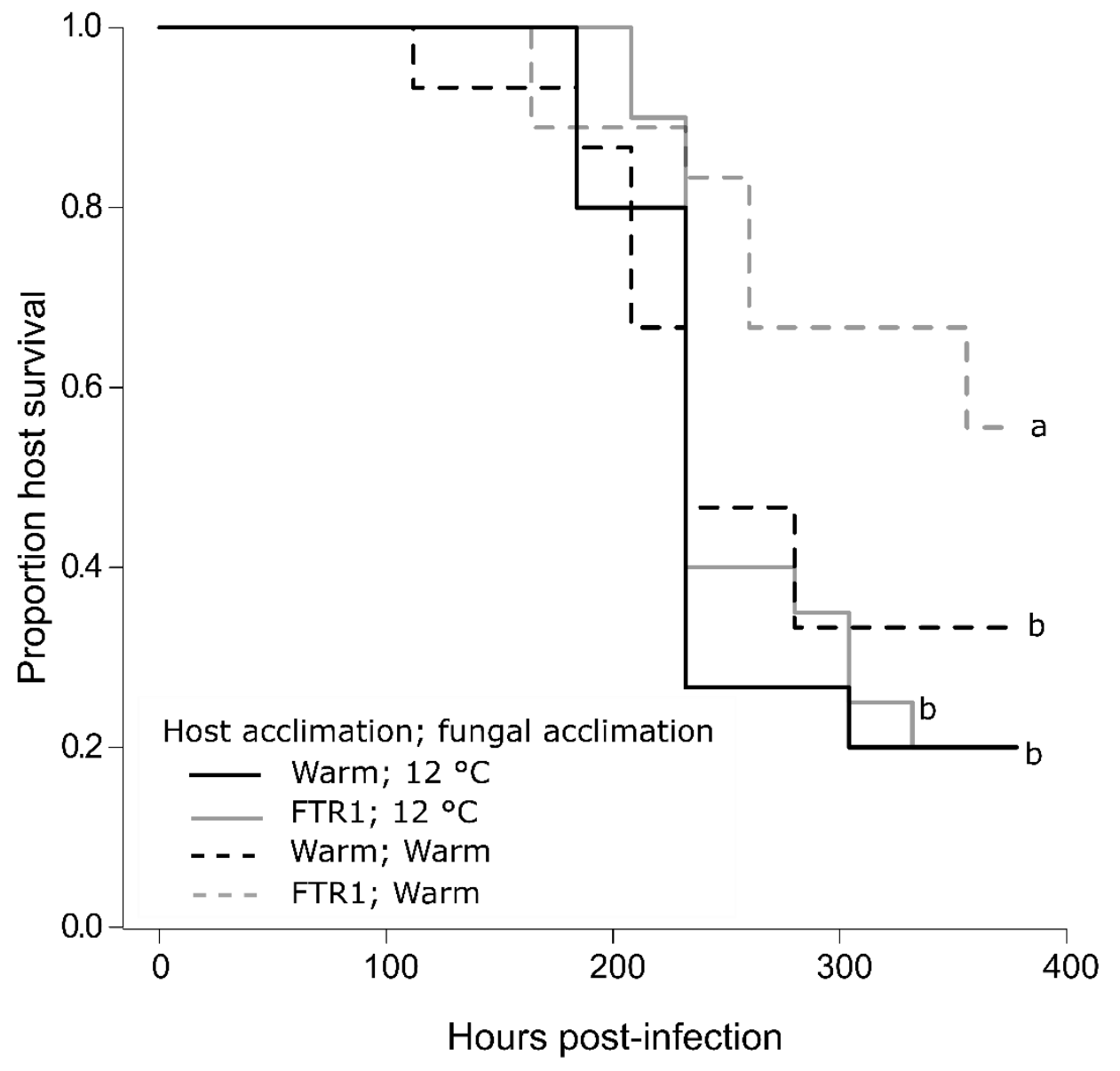

Figure 3. 


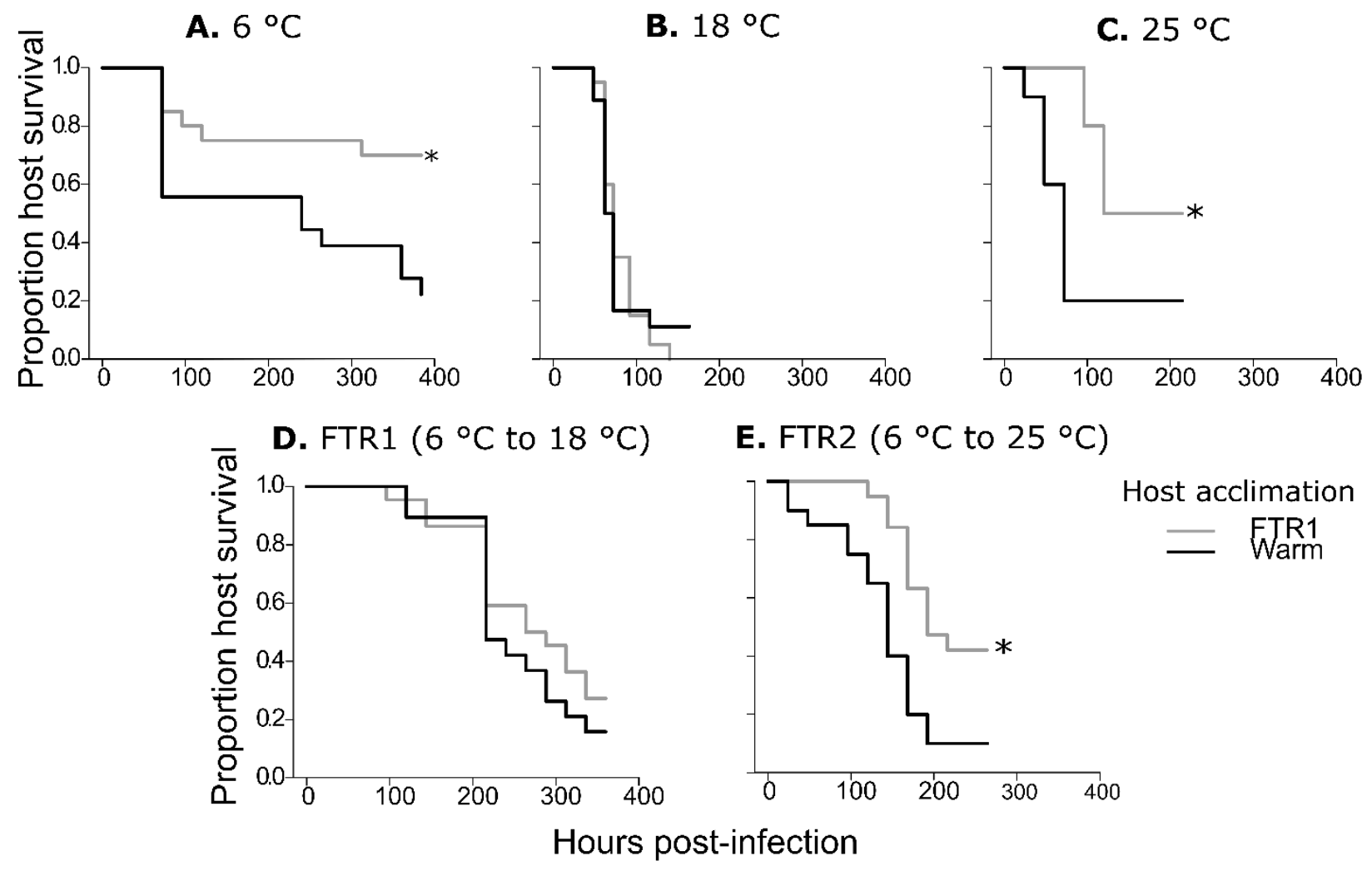

Figure 4. 


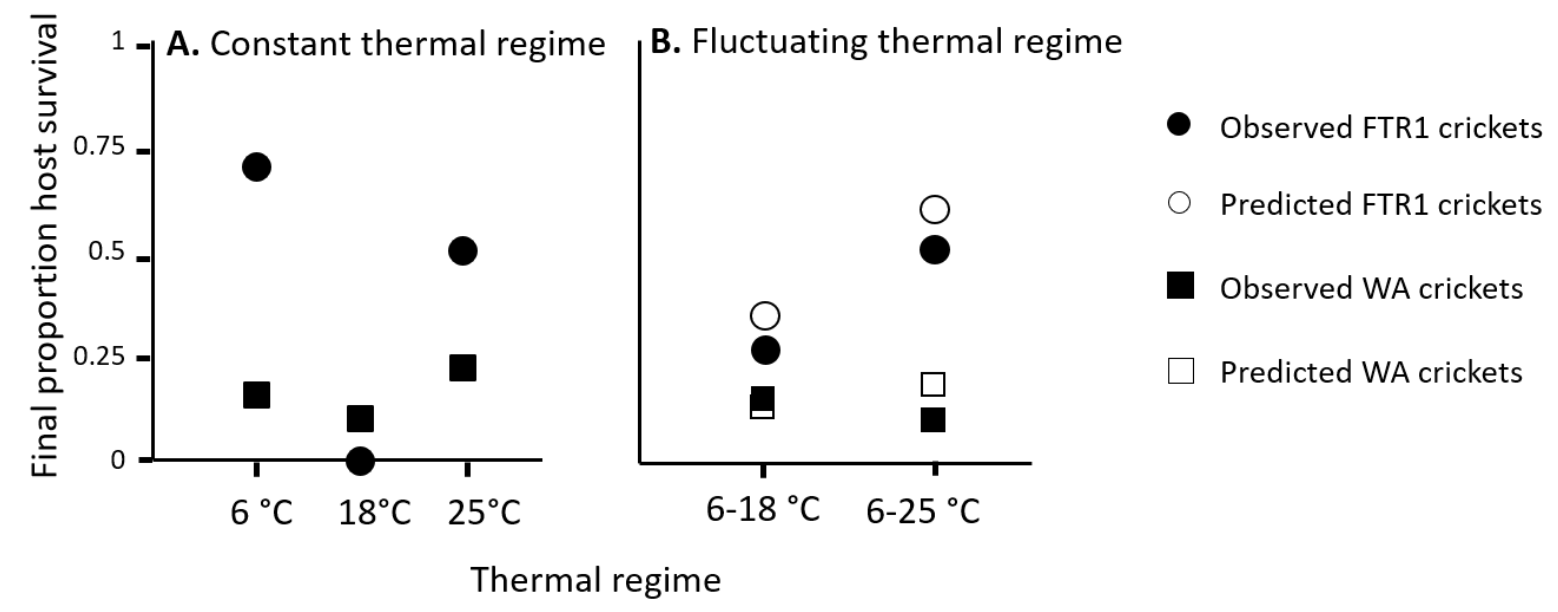

Figure 5. 
A. $18{ }^{\circ} \mathrm{C}$ switch to $6^{\circ} \mathrm{C}$

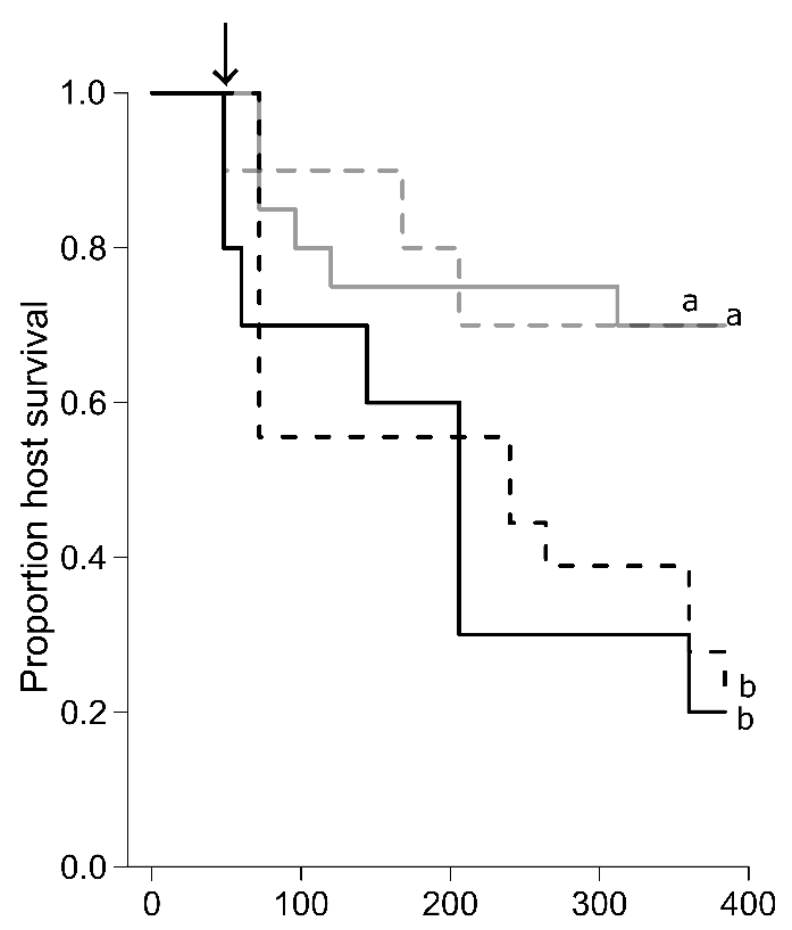

B. $6^{\circ} \mathrm{C}$ switch to $18^{\circ} \mathrm{C}$

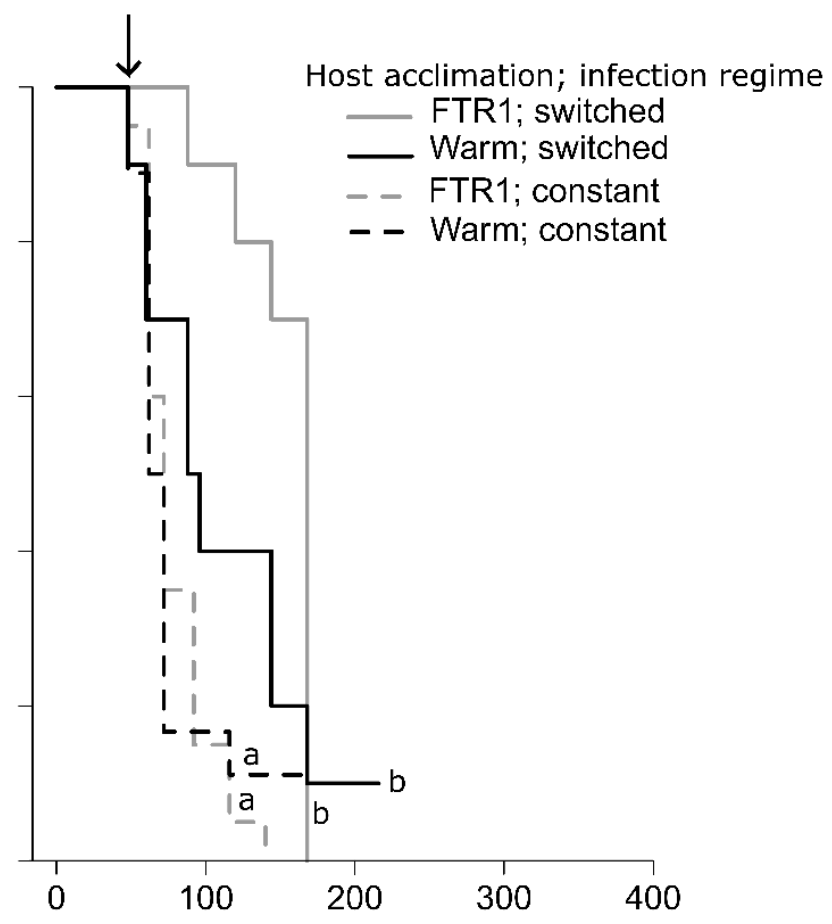

Hours post-infection

Figure 6. 
Host survival is independent of the thermal environment (including fluctuating temperatures)

A. Fluctuating thermal regime $6{ }^{\circ} \mathrm{C}$ to $18^{\circ} \mathrm{C}$

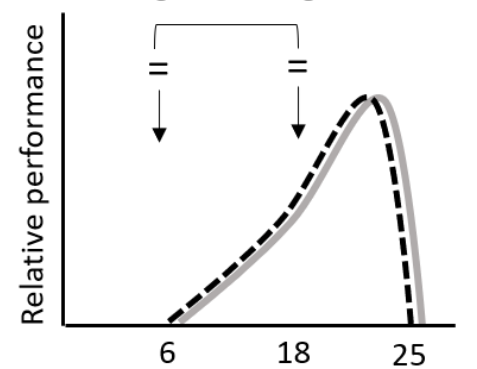

B. Fluctuating thermal regime $6{ }^{\circ} \mathrm{C}$ to $25^{\circ} \mathrm{C}$

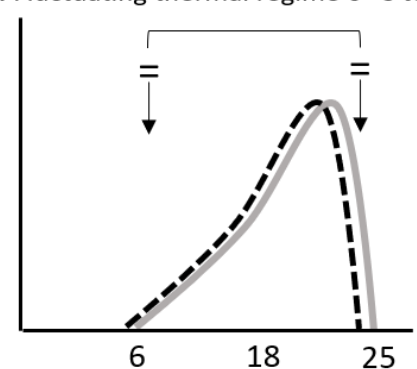

Host survival depends on fluctuations between advantageous and detrimental temperatures

C. Fluctuating thermal regime $6^{\circ} \mathrm{C}$ to $18^{\circ} \mathrm{C}$

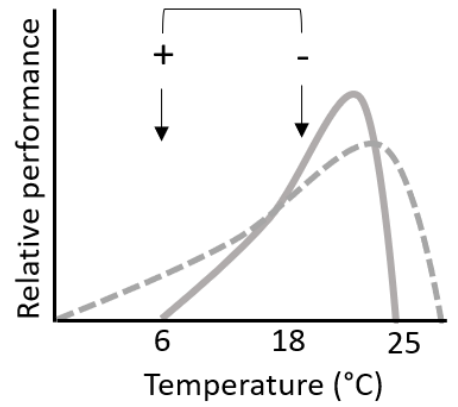

D. Fluctuating thermal regime $6{ }^{\circ} \mathrm{C}$ to $25^{\circ} \mathrm{C}$

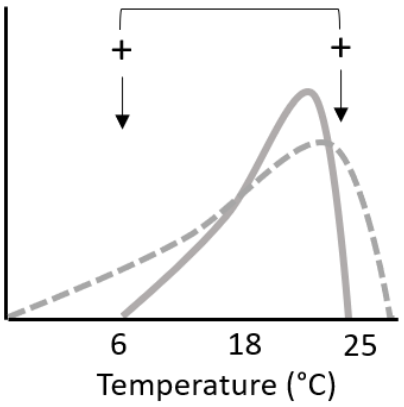

Figure 7. 